\title{
The immune system cell populations were increased in salt-induced hypertensive rats without an increase in the serum testosterone level (Short communication)
}

\author{
FO Awobajo, AE Okafor, HO Adebayo \\ Faculty of Basic Medical Sciences, Department of Physiology, College of Medicine, University of Lagos, \\ Lagos, Nigeria
}

Received: July 13,2017

Accepted: March 29, 2018

\begin{abstract}
The consumption of dietary salt has significantly increased globally, especially in the developed countries. High dietary salt intake has been linked to onset and complications in hypertension with a dimorphism tendency. There is scanty information about the influence of high salt diet on the immune cell population and androgen level in circulation. Male Sprague-Dawley rats of 8 weeks old were used for this study. They were divided into control (fed $0.1 \%$ salted feed) and salt-loaded groups (fed $8 \%$ salted feed) for 8 weeks. All experimental rats were allowed access to clean drinking water; daily feed consumption was measured in addition to weekly weight. On confirmation of hypertension using PowerLab ${ }^{\circledR}$ data acquisitions system, the rats were sacrificed and blood samples were collected into EDTA and sterile sample bottles. EDTA-blood samples were used for white blood cell and CD4 counts while the serum was used for hormonal assays. All salt-loaded rats became hypertensive, with a significant increase in total white blood cell, lymphocyte, neutrophil, monocyte, and CD4 cell counts. However, the eosinophil count was significantly decreased in salt-loaded rats. This study showed no change in the serum testosterone in salt-loaded male rats compared with control. In summary, dietary salt loading while precipitating hypertension also activated increased production of white blood cells and CD4 cells without any change in the serum testosterone level.
\end{abstract}

Keywords: dietary salt, immunity, differential white blood cell, lymphocytes, CD4, Sprague-Dawley rats

\section{Introduction}

Dietary salt contains sodium and chloride ions and its consumption has been increased across the globe along with numerous reported cardiovascular-related detrimental experiences $(3,6,18)$. The reported global increase in dietary salt consumption is a result of increased consumption of processed food treated with relatively high quantities of salts for preservation and taste enhancement $(6,7,11)$. Thus, the projected detrimental effects of high salt consumption, such as cardiovascular and renal diseases, are prevalent in the cities $(4,10)$. The role of chronic dietary salt consumption in the pathogenesis of cardiovascularrelated diseases is well documented $(5,19)$. However, there are scanty reports on the influence of high dietary salt consumption on the immune system. Okuda and Grollman (14) reported that hypertension can be induced in normotensive rats by transferring lymphocytes from hypertensive rats. This suggested that hypertension at some point

\footnotetext{
Corresponding author: Funmileyi Olubajo Awobajo

Faculty of Basic Medical Sciences, Department of Physiology, College of Medicine, University of Lagos, Room 006, Block F, idi-araba, Surulere, Lagos, Nigeria

Phone: +234 805341 6937; E-mail: funmi_bajo@yahoo.com
} 
precipitates vascular immune reaction, which can further worsen the hypertensive state by inducing cytokine-mediated vasoconstriction and aggravating the development of atherosclerosis $(8,12)$. The autonomic nervous system innervates the bone marrow, spleen, and peripheral lymphatic system with the parasympathetic branch dampening the cardiovascular (12), and with the sympathetic branch precipitating the pro-inflammatory effects (16). This claim about sympathetic effect on these tissues was buttressed by the observation that high-ambient sodium ion concentration around immune cells both in vivo and in vitro induced their proliferation and their cytokine production $(10,20)$. Thus, this observation suggests that the vascular immune reactions that follow hypertension may have been induced independently by chronic hypernatremia and not by pathophysiological responses to elevated blood pressure. This study was designed to investigate the effect of dietary salt loading on the proliferation of some specific immune cells, such as neutrophils, eosinophils, monocytes, lymphocytes, and CD4 cells, and its possible link to a change in serum testosterone level using laboratory rats.

\section{Materials and Methods}

\section{Animals}

A total of 18 male Sprague-Dawley (SD) rats of 8 weeks old weighing $100 \mathrm{~g}$ each were used for this study. They were housed in plastic cages at a population of six rats per cage at a room (daylight) temperature of about $29-32{ }^{\circ} \mathrm{C}$. All procedures including feeding, housing, sample collections, and humane euthanasia were in accordance with the Helzinki guidelines (16) for care and use of experimental animals as approved by the Institutional Health Research and Ethics Committee, College of Medicine, University of Lagos, Nigeria (CM/HREC/010/16/064).

\section{Group and treatment of rats}

They were divided into a control group, which was fed with a normal diet of $0.1 \%$ dietary salt (17) content and the salt-loaded group that was placed on a special rat feed containing $8 \%$ dietary salt. Both groups were fed with the corresponding diet for 8 weeks, throughout which their average weekly weight was monitored as a criterion for accessing feeding patterns. At the end of 8 weeks, three rats each from the two groups were anesthetized and their blood pressure parameters were determined using blood pressure transducer connected to the PowerLab $^{\circledR}$ (ADInstruments, USA) data acquisition instrument. Blood pressure was measured by direct cannulation of the rat's left carotid artery after the injection of urethanechloralose. Further procedure was only continued after the animals had been confirmed hypertensive. Thereafter, the remaining animals were sacrificed and blood samples were collected into 5-ml EDTA tubes and sterile sample bottles. Blood samples in sterile sample bottles were centrifuged at 3,000 rpm for $5 \mathrm{~min}$ to obtain serum for hormonal assay.

\section{Determination of CD4 count, differential white blood cell count, and estradiol and testosterone assay}

CD4 cell count was estimated using CD4 easy count kit (Sysmex Partec GmbH, Germany). Differential white blood cell count was estimated using automated blood cell analyzer. Serum testosterone and estradiol levels were assayed using ELISA kits (Rapid Labs, UK), according to the manufacturer's protocol. 
Statistical analysis

All data were analyzed with Graphpad prism-5 using two-way ANOVA, followed by Tukey-Kramer test as post-hoc test. The results were displayed as mean \pm SEM and the level of significance was placed at $p \leq 0.05$. Results were presented in tables and bar charts were also used for graphical representation.

\section{Results}

Feed consumption and weight gain during the period of salt loading

The salt-loaded rat recorded a decrease in body weight gain from the first to the third week of salt loading (control $=14.10 \pm 0.10$ and salt-loaded $=3.45 \pm 0.40 \mathrm{~g}$; Fig. 1A). Weight gain in salt-loaded group was, however, not different from that of control thereafter from third week of salt loading till the expiration of the experimental period. The weekly feed consumption was significantly reduced at the second week of salt loading (control $=9.83 \pm 0.51$ and saltloaded $=5.81 \pm 0.51 \mathrm{~g}$ ), while it was relatively the same thereafter when compared to the feed consumption of control rats. There was a significant increase in feed consumption in the salt-loaded rats at the sixth week of salt loading (Fig. 1B).

\section{Blood pressure in salt-loaded rats}

There was a significant increase in the values of all the blood pressure parameters that were measured, especially systolic (SBP), diastolic (DBP), pulse (PP), and mean arterial blood pressure (MABP) values were higher in all the rats after the 8 weeks of salt loading compared with those in control rats (Table I). SBP (control $=99.55 \pm 0.21$ and salt-loaded $=169.80 \pm$ 4.30 ), DBP (control $=86.16 \pm 0.10$ and salt-loaded $=142.90 \pm 3.40)$, MABP (control $=$ $90.74 \pm 11.73$ and salt-loaded $=151.87 \pm 3.70$ ), and PP (control $=13.24 \pm 0.10$ and saltloaded $=29.40 \pm 0.12$ ).

\section{Lymphocytes concentration in salt-loaded rats}

There was a significant increase in total white blood cell count in the circulation of salt-loaded rats (Fig. 2A; control $=7.37 \pm 0.17$ and salt-loaded $=10.60 \pm 0.52$ ). There was also a significant increase in lymphocyte count (Fig. 2B). The CD4 count was significantly increased in all salt-loaded rats (Fig. $2 \mathrm{C}$; control $=7.50 \pm 0.72$ and salt-loaded $=9.50 \pm 0.51$ ). The neutrophil


Fig. 1. Body weight gain (A) and average weekly feed consumption (B) in salt-loaded and control male rats. $*$ Significance level, $p \leq 0.05$. Result presented as mean $\pm \operatorname{SEM}(n=9$ rats/group) 
Table I. Blood pressure parameters and serum testosterone level in control and salt-loaded male rats $(n=9$ rats/group)

\begin{tabular}{|l|c|c|}
\hline Parameter & Control & Salt-loaded rat \\
\hline Systolic blood pressure $(\mathrm{mmHg})$ & $99.55 \pm 10.76$ & $169.80 \pm 4.30^{*}$ \\
\hline Diastolic blood pressure $(\mathrm{mmHg})$ & $86.16 \pm 12.28$ & $142.90 \pm 3.40^{*}$ \\
\hline Mean arterial blood pressure $(\mathrm{mmHg})$ & $90.74 \pm 11.73$ & $151.87 \pm 3.70^{*}$ \\
\hline Pulse pressure (mmHg) & $13.24 \pm 3.53$ & $29.40 \pm 1.60^{*}$ \\
\hline Serum testosterone level $(\mathrm{ng} / \mathrm{ml})$ & $0.96 \pm 0.03$ & $0.92 \pm 0.02$ \\
\hline
\end{tabular}

*Significant increase compared to control $(p \leq 0.05)$
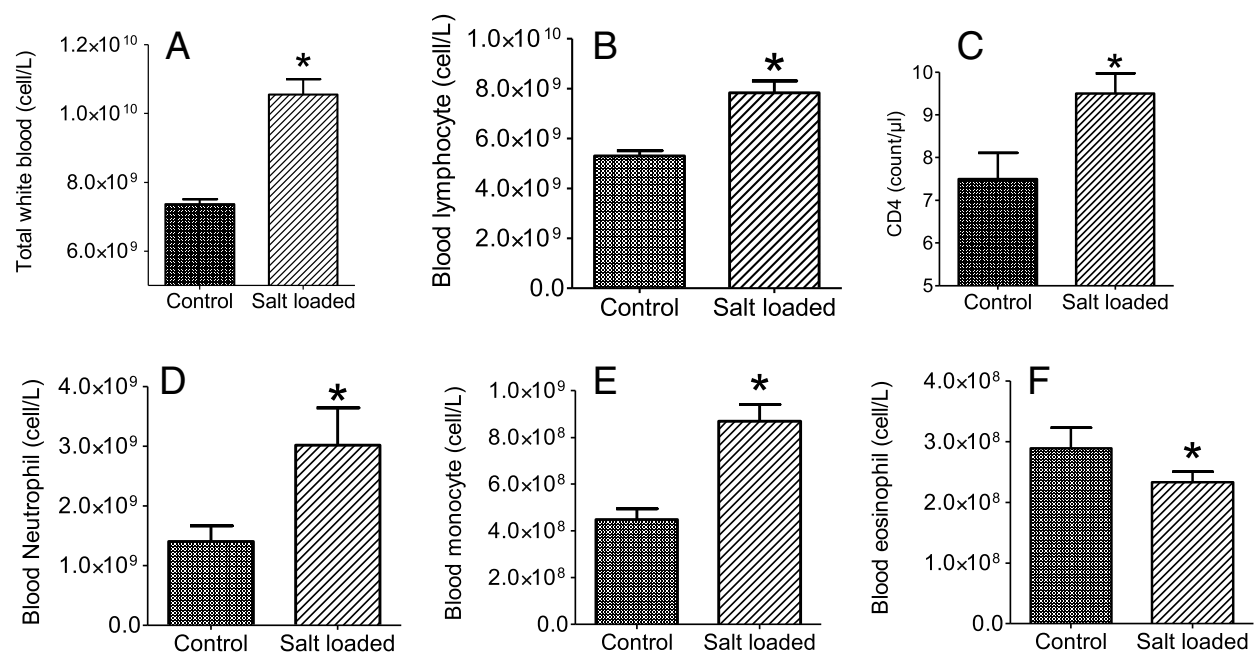

Fig. 2. Total white blood cell count (A), and the differential white blood cell concentration for lymphocytes (B), CD4 count (C), neutrophil (D), monocyte (E), and eosinophil (F) in blood samples from salt-loaded and control male rats. *Significance level, $p \leq 0.05$ ( $n=9$ rats/group)

concentration was significantly increased compared with control rats (Fig. 2D; control $=1.43 \pm$ 0.38 and salt-loaded $=2.46 \pm 0.50$ ). Monocyte concentration in the blood was significantly increased (Fig. 2E; control $=4.48 \pm 0.57$ and salt-loaded $=7.05 \pm 0.12$ ). However, the eosinophil concentration was significantly reduced (Fig. 2F; control $=0.29 \pm 0.04$ and saltloaded $=0.23 \pm 0.02$ ) in all salt-loaded rats compared with control rats.

\section{Serum testosterone level}

The serum testosterone level was not different in the salt-loaded rats compared with the control rats (Table I; control $=0.96 \pm 0.03$ and salt-loaded $=0.93 \pm 0.02$ )

\section{Discussion}

In this study, all the salt-loaded rats became hypertensive within 8 weeks. The recorded increased blood pressure in the salt-loaded rats in this study conformed to previously reported 
results in SD rats (17). There was a significant decrease in weight and thus, due to the initial reduced feed acceptance, we observed a decrease in weight gain in salt-loaded male rats between the first 2 weeks of the experiment (Fig. 1). All the salt-loaded rats gained adequate weight after the initial 2 weeks of feed rejection as the feed intake significantly improved (Fig. 1). Analysis of the blood samples revealed a significant increase in total white blood cell count in the salt-loaded rats compared with the control rats. The observed increase was the result of the significant increase in the circulating concentration of the neutrophils and monocytes (Fig. 2). The concentration of circulating monocytes, CD4 cells, and the granulocytes, especially the neutrophils, were significantly increased in the salt-loaded group, suggesting positive feedback stimulation of leucopoiesis. Other authors have also reported similar increase in the total white blood cell, monocyte, and interleukin-17producing CD4+ helper T-cell counts in salt-loaded rats and humans $(1,10,16,20)$. There are reports supporting that dietary salt loading is associated with dysfunction of the immune system, chronic systemic inflammation, and autoimmunity (13). These adverse effects have been postulated to be the real threat to the integrity of the various organs and tissues during hypertension (13). Neutrophils are important in immune reactions to bacterial infection and constitute about $60 \%$ of total white blood cells in circulation. Neutrophils, just like other granulocytes, are involved in innate immunity as opposed to adaptive immunity (15). A selective stimulation of the proliferation of the different white blood cells by dietary salt-loading was established in this experiment. However, the eosinophil count was significantly reduced as compared with all the other forms of white blood cells that were measured. This selective stimulation or inhibition of the proliferation of some of the white blood cell types may be the result of an interference with the differentiator inducers responsible for the differentiation of the uncommitted stem cells. The increase in the T-lymphocyte that include the helper inducer T-cell that serve as activator of the immune system may also have contributed to the increase in the leucocyte count as recorded in this study (2). Although several researchers have suggested the role of androgens in the modulation of immune functions (9), this study, however, recorded no significant change in serum testosterone level in salt-loaded rats (Table I).

\section{Conclusion}

The result of this study showed that high dietary salt loading in SD rats selectively stimulates the production of some immune cells while inhibiting others without any concomitant increase in plasma testosterone level.

\section{Acknowledgements}

The authors are grateful to Mr. Adejare of the Department of Physiology for the assistance in the invasive measurement of blood pressure.

\section{REFERENCES}

1. Adeniyi OS, Fasamade AA: Effect of dietary Zinc supplementation on salt induced hypertension in rats. Int. J. Pharmacol. 2, 485-491 (2006)

2. Alberts B, Johnson A, Lewis J, Raff M, Roberts K, Walter P (2002): Helper T cells and lymphocyte activation. In: Molecular biology of the cell (4th ed.), eds Alberts B, Johnson A, Lewis J, Raff M, Roberts K, Walter P, Garland Sciences, New York. Available at: https://www.ncbi.nlm.nih.gov/books/NBK26827/ 
3. Brown I, Tzoulaki I, Candeias V, Elliott P: Salt intakes around the world: implications for public health. Int. J. Epidemiol. 38, 791-813 (2009)

4. Croxford AL, Waisman A, Becher B: Does dietary salt induce autoimmunity? Cell Res. 23, 872-873 (2013)

5. Drenjancevic-Peric I, Jelakovic B, Lombard J, Kunert M, Kibel A, Gros M: High-salt diet and hypertension: focus on the renin-angiotensin system. Kidney Blood Press. Res. 34, 1-11 (2011)

6. Gutierrez OM: Sodium and phosphorus-based food additives: persistent but surmountable hurdles in the management of nutrition in chronic kidney disease. Adv. Chronic Kidney Dis. 20, 150-156 (2013)

7. James WP, Ralph A, Sanchez-Castillo CP: The dominance of salt in manufactured food in the sodium intake of affluent societies. Lancet 329, 426-429 (1987)

8. Kanbay M, Chen Y, Solak Y, Sanders PW: Mechanisms and consequences of salt sensitivity and dietary salt intake. Curr. Opin. Nephrol. Hypertens. 20, 37-43 (2012)

9. Lai J, Lai K, Zeng W, Chuang K, Altuwaijri S, Chang C: Androgen receptor influences on body defense system via modulation of innate and adaptive immune systems. Am. J. Pathol. 181, 1504-1512 (2012)

10. Lucca LE, Hafler DA: Sodium-activated macrophages: the salt mine expands. Cell Res. 25, 885-886 (2015)

11. Mattes RD, Donnelly D: Relative contributions of dietary sodium sources. J. Am. Coll. Nutr. 10, 383-393 (1991)

12. National Research Council, Division on Earth and Life Studies, Institute for Laboratory Animal Research, Committee (1996): Guide for the care and use of laboratory animals (8th ed.), National Academy Press, Washington, DC, pp. 11-124

13. O'shea JJ, Jones RG: Autoimmunity: rubbing salt in the wound. Nature 496, 437-439 (2013)

14. Okuda T, Grollman A: Passive transfer of autoimmune induced hypertension in the rat by lymph node cells. Tex. Rep. Biol. Med. 25, 257-264 (1967)

15. Rosales C, Demaurex N, Lowell CA, Uribe-Querol E: Neutrophils: their role in innate and adaptive immunity. J. Immunol. Res. 2016, 1469780 (2016)

16. Singh MV, Chapleau MW, Harwani SC, Abboud FM: The immune system and hypertension. Immunol. Res. 59, 243-253 (2014)

17. Sofola AO, Dina TA, Egbe PE, Owolabi OA: Dietary salt loading enhances bioreflex sensitivity in Sprague Dawley rats. Niger. J. Physiol. Sci. 7, 95-99 (1991)

18. Terry J: The major electrolytes; sodium, potassium, and chloride. J. Intraven. Nurs. 17, 240-247 (1994)

19. Toshiro F: Mechanisms of salt induced hypertension: focus on adrenal and sympathetic nervous system. J. Am. Soc. Nephrol. 25, 1148-1155 (2014)

20. Yi B, Titze J, Rykova M, Feuerecker M, Vassilieva G, Nichiporuk I, Schelling G, Morukov B, Choukèr A: Effects of dietary salt levels on monocytic cells and immune responses in healthy human subjects: a longitudinal study. Transl. Res. 166, 103-110 (2015) 